\title{
Research on Impact Factors of Smart Elderly Care Mode and the Corresponding Industry Example
Exaestionnaire Data of Some Cities in Jiangsu Province as An
}

\author{
Fengjuan Liu ${ }^{1,2, \mathrm{a}^{*}}$, Yuechen $\mathrm{Liu}^{3, \mathrm{~b}}$, Chun Yang ${ }^{4, c *}$ \\ ${ }^{1}$ Wuxi Environmental Science and Engineering Research Center, Jiangsu \\ ${ }^{2}$ Wuxi Society of Population and Social Development Wuxi, China \\ ${ }^{3}$ College of Management and Economics Tianjin University Tianjin, China \\ ${ }^{4}$ Jiangsu Population Association, Jiangsu, Nanjing, China
}

\begin{abstract}
With the development of Internet of things technology, the smart elderly care mode is attracting more and more attention. Based on the questionnaire data of adult residents in some cities of Jiangsu Province, this paper analyzes the multiple linear regression model between the intelligent elderly care mode and its possible influencing factors. And it can be found that for participants aged 59 and under, their educational level, blood type, professional identity and age have a significant impact on intelligent old-age care mode. For participants aged 60 and over, only their educational level and age have a significant impact on the smart old-age care approach. Finally, this paper puts forward some suggestions about the development of industries related to intelligent elderly care to build an integrated intelligent community oldage care pattern, integrated pattern of intelligent home-based care or integrated smart home-based care service center, adjust and perfect the existing elderly care institutions, and improve intelligence old-age care institutions pattern to promote the development of intelligent industry related to smart elderly care.
\end{abstract}

\section{INTRODUCTION}

With the deepening of the aging society, the problem about the old-age care is not only a matter for the family or individuals, but also a matter for the relevant departments of the state. Meanwhile, people are paying more and more attention to the convenience and happiness of old age life. With the advance of the Internet of Things technology, artificial intelligence products increasingly penetrate into various fields. The smart elderly care modes such as smart community elderly care, smart home-based elderly care and smart institution elderly care are gradually coming into people's vision, and the smart old-age care mode are gaining more and more attention. Smart care for the aged that was first proposed by the British Life Trust, also known as the "full smart elderly system", namely, makes use of advanced Internet, cloud computing, wearable and other new generation of information technology like technologies of Internet of Things to build a kind of the Internet of Things system and information platform for the family-oriented elderly care, community old-age care and institutional elderly care to integrate the resources of the government, society, and community families, thus provide more convenient, efficient and flexible service models of public management innovation for the elderly. Therefore, many

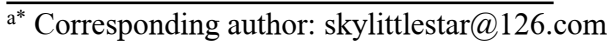

bxzxlxb@163.com

c* Corresponding author: 1279347249@qq.com
}

scholars have made some researches on the intelligent elderly care and the related industry development.

Firstly, some scholars have done some studies about health care services and mutual assistance in smart communities. For example, Li, Lu, Liang, et al(2011) introduced in their paper smart community applications about neighborhood watch and pervasive healthcare with supporting techniques[1]. Secondly, the research on auxiliary robots and smart home facilities is carried out in order to improve the elderly's ability and level of healthy life. For example, Saunders, Syrdal, Koay, et al (2016) have demonstrated that it is possible for careers, relatives and the elderly themselves to use personalization of an autonomous robot or assistive robots in a domestic "smart-home" environment[2]. Stojkoska and Trivodaliev (2017) propose a smart home holistic framework and identify a smart home management model based on it [3]. Suryadevara and Mukhopadhyay (2012) suggest a mechanism for estimation of elderly well-being condition based on application of house-hold appliances connected through various sensing units to determining wellness of the elderly [4]. The research contributes to the real-time monitoring and assessing the elderly activities at home. Wong, Chang, Ke, et al (2012) have developed a new Intelligent Comprehensive Interactive Care (ICIC) system to provide comprehensive services for elderly care including medical care, diet, living, transportation, education, entertainment, and safety[5]. Thirdly, some 
scholars have done some research on the implementation of intelligent system. For example, Salman, Salman, Jahangirian, et al(2016) deemed that Smart Home technology is the future of the technology related to the residential, which is intended to deliver and distribute the number of services inside and outside the house via network devices, and "the smart system can remotely control the lighting and heating or cooling"[6]. Dawadi, Cook and Schmitteredgecombe (2016) think that smart home technologies provide potential benefits for helping clinicians in order to check the physical condition of residents by automating health monitoring and well-being assessment, and put forward that "it is feasible to predict clinical scores using smart home sensor data and learningbased data analysis" [7]. Ransing and Rajput (2015) proposed a set of smart home system based on Wireless Sensor Network for elder people to help them carry out their work at ease and provide safe, sound and secure living for them[8]. Finally, some scholars have done their research on the influence of blood type and educational background on people's personality, because personality will affect people's behaviors and activities. For example, the Japanese scholar, Furukawa Takeji that put forward the theory of the relationship between personality and blood group based on the survey in 1927 [9]. Jogawar (1983) found the relationship between the people's blood type and their sentiment [10]. Jackson (2011) believes that educational experiences can cause changes in personality traits and vice-versa[11].

However, few scholars have done studies about the intelligent elderly care mode from the comprehensive perspective of blood type, age, educational level and occupational identity, so that is how this paper works. But some scholars have studied the influencing factors of intelligent elderly care service, including the education level. For example, Zhang and Xu (2016) suggest that the factors influencing the demand of the elderly for intelligent care services involves financial situation, physical health, cultural lives and educational background[12].

\section{DATA SELECTION AND MODEL DETERMINATION}

The development of Internet of Things technology has promoted the continuous upgrading of artificial intelligence industry, which drives the development of intelligent endowment mode. In order to find out what factors might affect the application of smart technology in old-age care, questionnaires were given to adults aged 59 and under who were already working and to elderly people aged 60 and over. Finally, 1324 valid questionnaires were collected from people aged 59 and below, and 649 valid questionnaires were collected from elderly people aged 60 and above. In this questionnaire about elderly care, Internet of Thing technology can be reflected in smart community, smart home and smart elderly care institutions. It then needs to be figured out what factors, such as age, blood type, educational level and occupation, would influence the people's choice for smart elderly care. Therefore, the old-age care mode is taken as the dependent variable, and the age, educational level, blood type and occupation of the respondents are taken as independent variables to conduct multiple linear regression. The multiple linear regression model is expressed as (1).

$$
\begin{aligned}
& y_{i}=\beta_{0}+\beta_{1} x_{1 i}+\beta_{2} x_{2 i}+\beta_{3} x_{3 i}+\beta_{4} x_{4 i}+\varepsilon_{i} \\
& \text { where, for } i=n \text { observations } \\
& y_{i}=\text { dependent variable } \\
& x_{1 i}=\text { age, }, x_{2 i}=\text { educationlevel, } \\
& x_{1 i}=\text { bloodtype, } x_{2 i}=\text { career } \\
& \beta_{\mathbf{0}}=y \text {-intercept (constant term) } \\
& \beta_{j}=\text { slope coefficients for each explanatory variable } \\
& \text { ( } j=\mathbf{1}, \mathbf{2}, \mathbf{3}, \mathbf{4}) \\
& \varepsilon_{i}=\text { themodel's errorterm(also knownas the residuals) }
\end{aligned}
$$

In the valid questionnaire, the age distribution, educational level, blood type distribution and occupational status of the participants aged 59 and below are shown in Fig. 1-4.

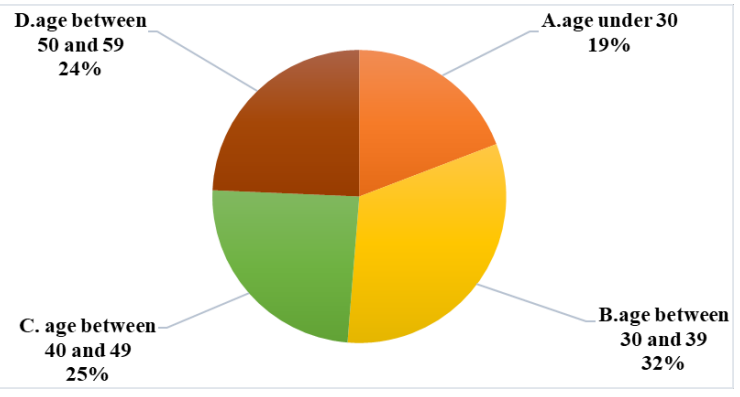

Figure 1. Age distribution of participants aged 59 years and below.

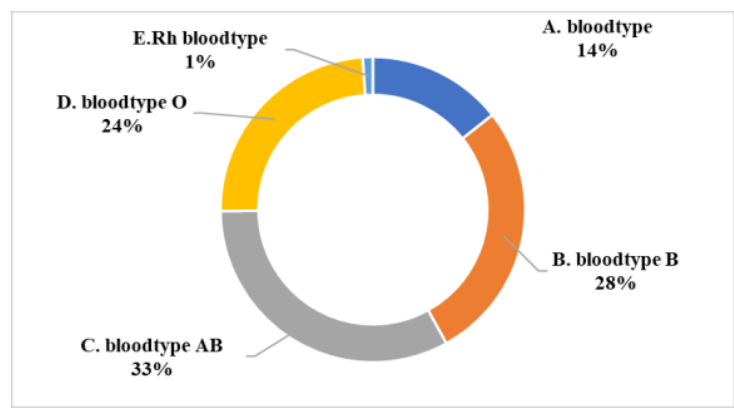

Figure 2. Blood type distribution of participants aged 59 years and under.

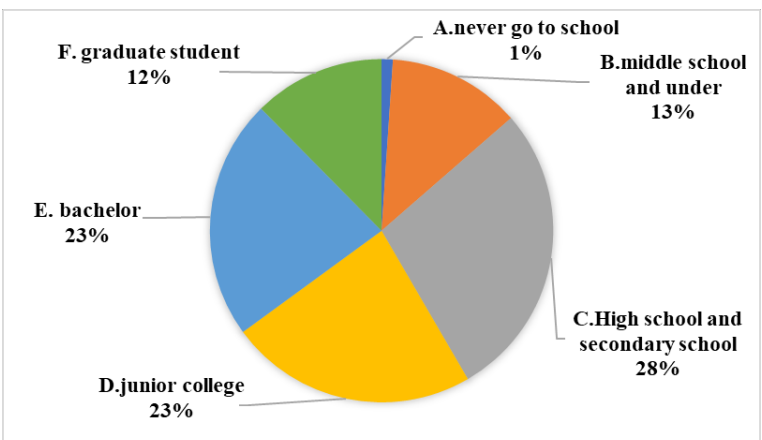

Figure 3. Distribution of educational levels of participants aged 59 years and below. 


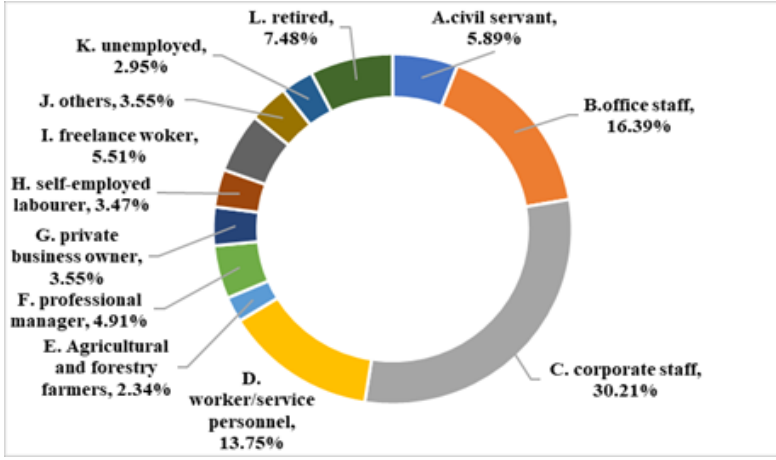

Figure 4. Occupation distribution of participants aged 59 years and below.

Obviously, the highest proportion is between the ages of 30 and 59. This paper does not consider the Rh blood group for the relatively small number of $\mathrm{Rh}$ blood group. The proportion of blood group $\mathrm{AB}$ and $\mathrm{B}$ is relatively high, while the proportion of blood group A is the lowest. Moreover, the proportion of the respondents with the high school to undergraduate education is relatively high in line with the educational background below the level of large and medium-sized cities. In addition, the number of employees in enterprises and public institutions is also relatively high.

The age distribution, educational level and blood type distribution of participants aged 60 and above are shown in Fig. 5-7. It is clear that people under the age of 79 and with blood groups $\mathrm{AB}$ and $\mathrm{B}$ both accounted for the highest proportion and the number of people with junior middle school and under is the highest.

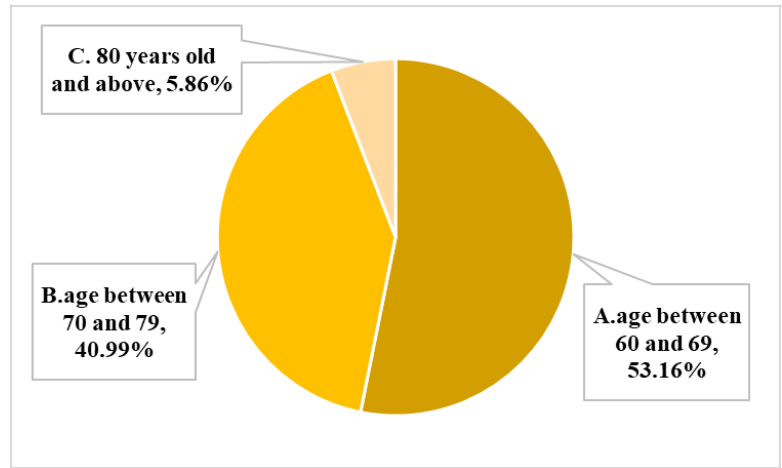

Figure 5. Age distribution of participants aged 60 and above.

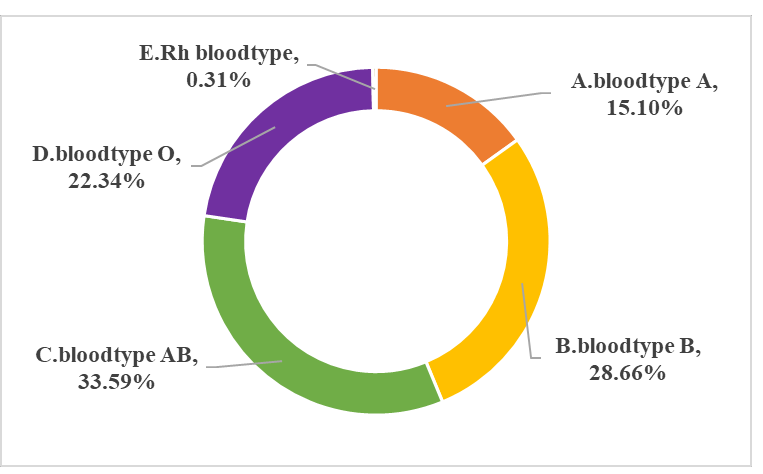

Figure 6. Blood type distribution of participants aged 60 years and under.

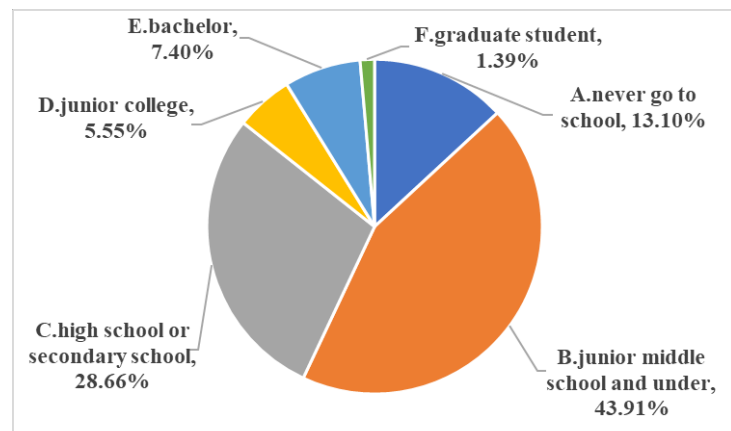

Figure 7. Distribution of educational levels of participants aged 60 and below.

According to dada in table 3 for the people under 59, it is obvious for the researchers to find the future preferences of aged care services and the development trend of the elderly service industry chain. That is to say, the people are more inclined to the elderly care services with enjoyment and convenience, and intelligent care in the future. In addition, the people pay more attention to mental health, and the demand for intelligent medical treatment, lifelong education, leisure and entertainment is increasing.

\section{ANALYSIS OF INFLUENCING FACTORS OF THE PREFERENCE FOR SMART ELDERLY CARE MODE}

\subsection{Analysis of the Causal Relationship between the Influencing Factors and the Way of Smart Elderly Care}

For the people aged 59 and below, the result of the multiple linear regression between the influencing factors and smart community elderly care mode is shown in Table 1.

TABLE I. THE REGRESSION RESULTS BETWEEN SMART COMMUNITY ELDERLY CARE AND ITS IMPACT FACTORS

\begin{tabular}{|c|l|c|c|c|c|}
\hline \multicolumn{2}{|c|}{ Smart community elderly care } & $\begin{array}{c}\text { Regression } \\
\text { coefficient }\end{array}$ & P value & T value & VIF \\
\hline \multirow{2}{*}{$\begin{array}{c}\text { independent } \\
\text { variables }\end{array}$} & Age & -0.033 & $0.011^{*}$ & -2.556 & 1.37 \\
\cline { 2 - 6 } & Education level & 0.086 & $0.000^{* *}$ & 8.022 & 1.327 \\
\cline { 2 - 6 } & Blood type & 0.042 & $0.001^{* *}$ & 3.484 & 1.102 \\
\hline
\end{tabular}




\begin{tabular}{|l|l|c|c|c|c|} 
& $\begin{array}{l}\text { Occupational } \\
\text { identity }\end{array}$ & -0.013 & $0.001^{* *}$ & -3.449 & 1.141 \\
\hline \multicolumn{3}{|c|}{$* \mathrm{p}<0.05 * * \mathrm{p}<0.01$} \\
\hline
\end{tabular}

It can be found that the statistical results are significant; Variance Inflation Factor (VIF) values in the model are all around 1 and they are less than 5, which means that there is no multicollinearity problem in the model. Therefore, age, educational level, blood type and occupational identity will all have an impact on the selection of smart community old-age care mode with advanced IoT supporting facilities, smart medical diagnosis system and smart home. Age and occupation identity will have a significant negative impact on the smart community elderly care mode, while educational level and blood type will have a significant positive impact on the smart community elderly care mode.

The multiple linear regression results between intelligent home-based elderly care and its influencing factors are shown in Table 2.

TABLE II. THE REGRESSION RESULTS BETWEEN SMART HOME-BASED ELDERLY CARE AND ITS IMPACT FACTORS

\begin{tabular}{|c|c|c|c|c|c|}
\hline \multicolumn{2}{|c|}{$\begin{array}{c}\text { Smart home-based } \\
\text { elderly care }\end{array}$} & $\begin{array}{c}\text { Regression } \\
\text { coefficient }\end{array}$ & P value & T value & VIF \\
\hline \multirow{4}{*}{$\begin{array}{c}\text { independent } \\
\text { variables }\end{array}$} & Age & 0.035 & $0.003^{* *}$ & 2.985 & 1.37 \\
\cline { 2 - 6 } & Education level & 0.084 & $0.000^{* *}$ & 8.813 & 1.327 \\
\cline { 2 - 6 } & Blood type & 0.022 & $0.042^{*}$ & 2.031 & 1.102 \\
\cline { 2 - 6 } & $\begin{array}{c}\text { Occupational } \\
\text { identity }\end{array}$ & -0.01 & $0.003 * *$ & -2.974 & 1.141 \\
\hline \multicolumn{4}{|c|}{$\mathrm{p}<0.05 * * \mathrm{p}<0.01$} \\
\hline
\end{tabular}

The VIF value in the model is the same as the previous analysis, which also indicates that there is no multicollinearity problem in the model. Therefore, the participants' professional identity, age, education level and blood type have a significant impact on smart home-based elderly care with advanced Internet facilities, intelligent medical diagnosis system and intelligent household, the professional identity has a significant negative effect on smart home-based elderly care, while the age, education level and blood type have a significant positive influence on smart home-based elderly care.

According to the results of linear regression, age cannot influence the choice of intelligent elderly care institutions mode. Therefore, the multiple linear regression results between intelligent elderly care institutions mode and its influencing factors without considering age are shown in Table 3.

TABLE III. THE REGRESSION RESULTS BETWEEN SMART OLD-AGE CARE INSTITUTION MODE AND ITS IMPACT FACTORS

\begin{tabular}{|l|l|c|c|c|c|}
\hline \multicolumn{2}{|c|}{ Smart old-age care institution } & $\begin{array}{c}\text { Regression } \\
\text { coefficient }\end{array}$ & P value & T value & VIF \\
\hline \multirow{3}{*}{$\begin{array}{l}\text { independent } \\
\text { variables }\end{array}$} & Education level & 0.06 & $0.000^{* *}$ & 8.364 & 1.121 \\
\cline { 2 - 6 } & Blood type & 0.019 & $0.022^{*}$ & 2.29 & 1.001 \\
\cline { 2 - 6 } & $\begin{array}{l}\text { Occupational } \\
\text { identity }\end{array}$ & -0.01 & $0.000^{* *}$ & -3.557 & 1.122 \\
\hline \multicolumn{4}{|l|}{$* \mathrm{p}<0.05 * * \mathrm{p}<0.01$} \\
\hline
\end{tabular}

The statistical results were significant, and the VIF values in the model were all less than 5, which also indicated that there was no multicollinearity problem in the model. Therefore, educational level, blood type and occupational identity will have a significant impact on intelligent elderly care institutions mode with advanced supporting facilities of the Internet of things, intelligent medical care or intelligent care, intelligent furniture and even all-round auxiliary robot nursing. Among them, the occupational identity of participants has a significant negative impact on intelligent elderly care institutions, while their educational level and blood type have a significant positive impact on intelligent elderly care institutions mode.

For people aged 60 and over, the results of the multiple linear regression model showed that there was no significant causal relationship between the elderly care mode and its influencing factors like blood type and occupation identity.

Therefore, only the regression relationships between the elderly care mode and its influencing factors like educational level and age are considered here. The results of multiple linear regression between smart community old-age care and its influencing factors like educational level and age are shown in Table 4.

TABLE IV. THE REGRESSION RESULTS BETWEEN SMART COMMUNITY OLD-AGE CARE AND ITS IMPACT FACTOR

\begin{tabular}{|c|l|c|c|c|c|}
\hline \multicolumn{2}{|c|}{ Smart community elderly care } & $\begin{array}{c}\text { Regression } \\
\text { coefficient }\end{array}$ & P value & T value & VIF \\
\hline \multirow{2}{*}{$\begin{array}{c}\text { independent } \\
\text { variables }\end{array}$} & Education level & 0.095 & $0.000^{* *}$ & 2.985 & 1.049 \\
\cline { 2 - 6 } & Age & -0.047 & $0.021 *$ & 8.813 & 1.049 \\
\hline \multicolumn{7}{|c|}{$* \mathrm{p}<0.05 * * \mathrm{p}<0.01$} \\
\hline
\end{tabular}


Since the value of VIF is 1.049, there is no multicollinearity problem in this model. Thus, the education level and age of participants will have a significant impact on the smart community elderly care, among which their education level will have a significant positive impact on the choice of smart community elderly care mode, and their age will have a significant negative impact on the choice of smart community elderly care mode.

The results of multiple linear regression between educational level and age and intelligent home-based care are shown in Table 5.

TABLE V. THE REGRESSION RESULTS BETWEEN SMART HOME-BASED ELDERLY CARE AND ITS IMPACT FACTORS

\begin{tabular}{|c|l|c|c|c|c|}
\hline \multicolumn{2}{|c|}{ Smart home-based elderly care } & $\begin{array}{c}\text { Regression } \\
\text { coefficient }\end{array}$ & P value & T value & VIF \\
\hline \multirow{2}{*}{$\begin{array}{c}\text { independent } \\
\text { variables }\end{array}$} & Education level & 0.095 & $0.000^{* *}$ & 8.546 & 1.049 \\
\cline { 2 - 6 } & Age & -0.073 & $0.000^{* *}$ & -3.572 & 1.049 \\
\hline \multicolumn{5}{|c|}{$* \mathrm{p}<0.05 * * \mathrm{p}<0.01$} \\
\hline
\end{tabular}

It can be found that under the condition of significant statistical results, VIF is 1.049 as before, which indicates that there is no collinearity problem. Thus, the educational level and age of participants will have a significant impact on the smart home-based elderly care mode. Among them, the educational level of participants will have a significant positive impact on the smart home-based elderly care mode. Their age will have a significant negative impact on the smart home elderly care mode.

TABLE VI. THE REGRESSION RESULTS BETWEEN SMART OLDAGE CARE INSTITUTION MODE AND ITS IMPACT FACTORS

\begin{tabular}{|c|l|c|c|c|c|}
\hline \multicolumn{2}{|c|}{$\begin{array}{c}\text { Smart old-age care } \\
\text { institution }\end{array}$} & $\begin{array}{c}\text { Regression } \\
\text { coefficient }\end{array}$ & P value & $\begin{array}{c}\text { T } \\
\text { value }\end{array}$ & VIF \\
\hline \multirow{2}{*}{$\begin{array}{c}\text { independent } \\
\text { variables }\end{array}$} & $\begin{array}{l}\text { Education } \\
\text { level }\end{array}$ & 0.048 & $0.000^{* *}$ & 6.527 & 1.049 \\
\cline { 2 - 6 } & Age & -0.027 & $0.048 *$ & - & 1.049 \\
\hline \multicolumn{7}{|c|}{$* \mathrm{p}<0.05 * * \mathrm{p}<0.01$} \\
\hline
\end{tabular}

The results of multiple linear regression between smart old-age care institution mode and its influencing factors like educational level and age are shown in Table 6 above.

It can be found that the value of VIF 1.049, which indicates that there is no collinearity problem in the model. The educational level and age of participants will have a significant impact on the choice of the mode of smart elderly care institution. Among them, the educational level of participants will have a significant positive impact on the choice of the mode of smart elderly care institution. Their age will have a significant negative impact on the demand for the aged in smart care institutions.

\subsection{Analysis of Influencing Factors of Choosing Smart Elderly Care Mode}

According to the previous analysis, it can be known that the age of a person will have an impact on the choice of smart elderly care mode. For people aged 59 and below, the degree of impact is shown in Figure 8-9. In the future, people who choose smart community or smart home care for their parents are mainly under the age of 50. Among those who choose smart community elderly care, people under the age of 30 account for the highest proportion. The people aged between 40 and 49 years old account for the highest proportion of those who choose smart homebased elderly care.

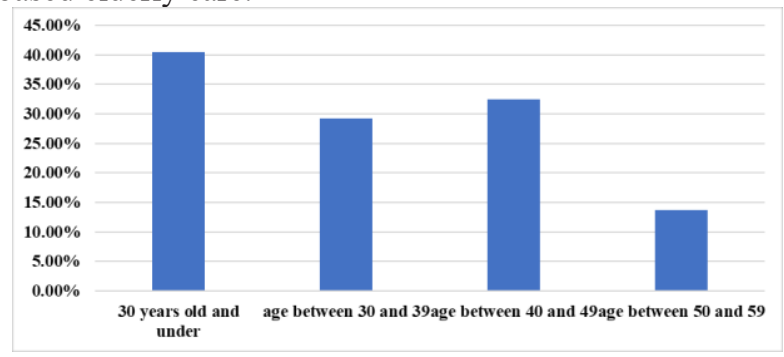

Figure 8. Proportion of people of all ages choosing smart community elderly care mode.

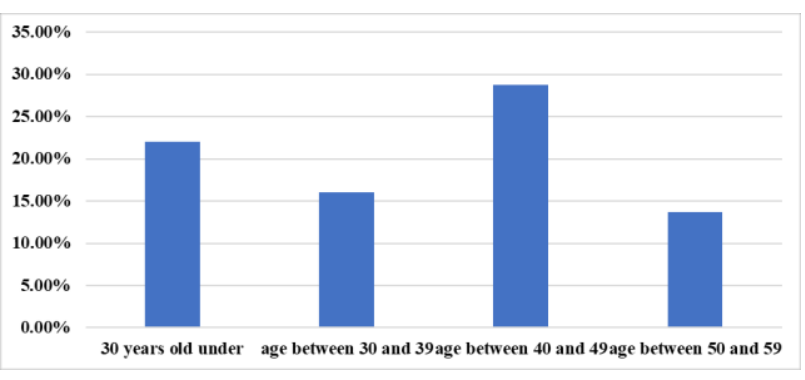

Figure 9. Proportion of people of all ages choosing smart home-based care.

In the previous analysis, it is also mentioned that different educational levels have a certain positive impact on intelligent elderly care mode. The specific impact results are shown in Figure 10-12. With the rise of education level, people's demand for smart communities, smart homes and smart pension institutions is increasing, especially for those with a bachelor's degree, followed by those with a postgraduate degree. In addition, it can also be seen from the figures that the preference of people for smart community elderly care mode is higher than that for smart home-based elderly care mode which in turn is higher than that for institutional elderly care mode. This shows that people prefer community elderly care mode, followed by smart home-based elderly care, and then smart elder care institutions mode. 


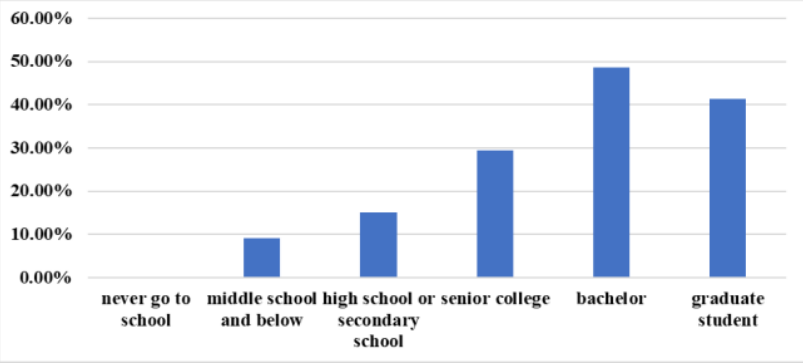

Figure 10. Proportion of people with different educational levels in smart community for elderly.

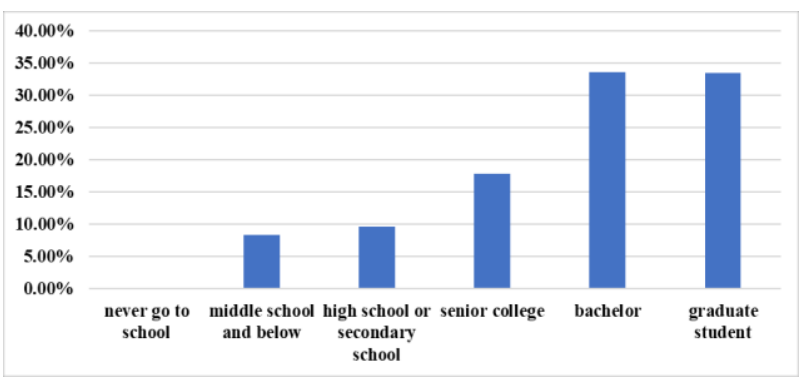

Figure 11. Proportion of people with different educational levels choosing smart home for the elderly care.

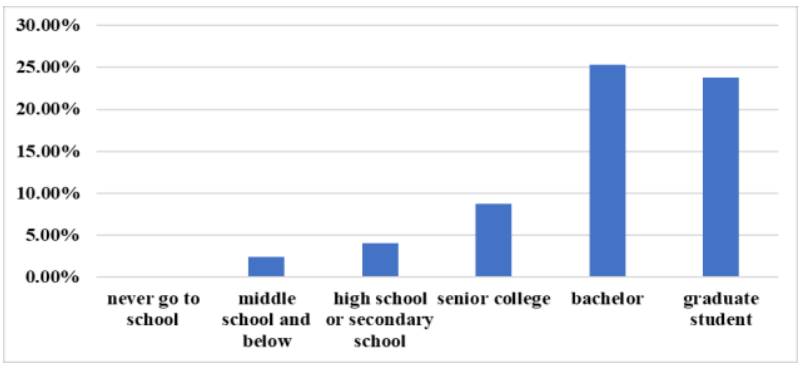

Figure 12. Proportion of people with different educational levels in smart elderly care service institutions

In the previous linear regression analysis, it can be known that the blood type of participants has a significant positive impact on the choice of intelligent elderly care mode, and the specific impact degree is shown in Figure 13-15.

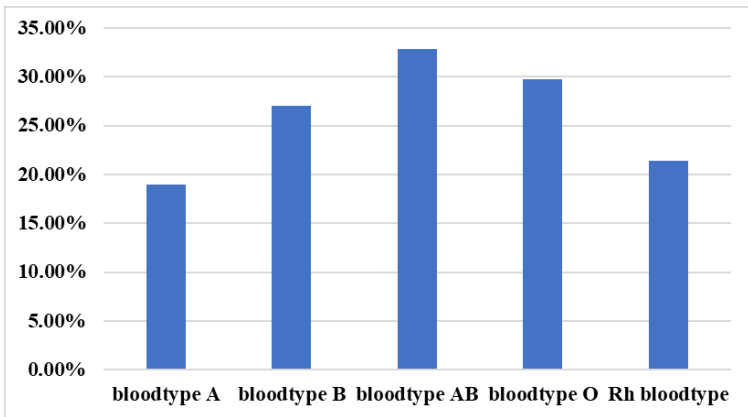

Figure 13. The proportion of each blood type selecting the smart community elderly care.

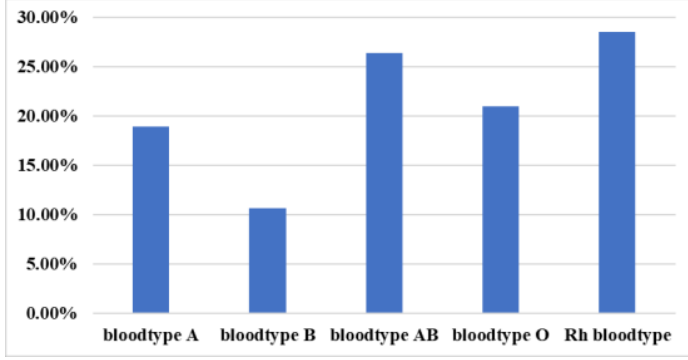

Figure 14. Proportion of blood types selecting for smart homebased elderly care.

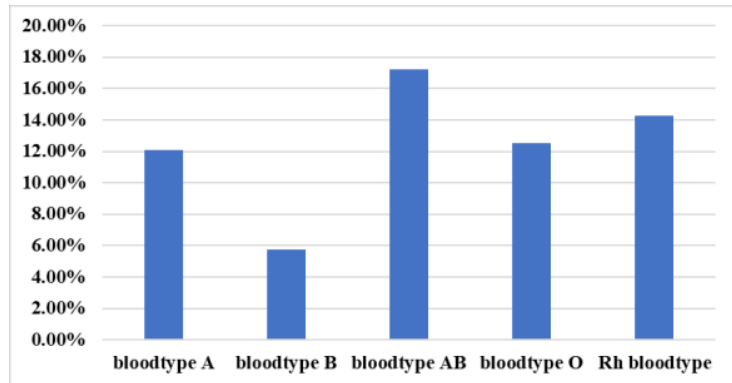

Figure 15. The proportion of each blood type in the smart elderly care institution

Due to the small number of Participants with blood group $\mathrm{Rh}$, the selection of blood group $\mathrm{Rh}$ is not considered for the time being. For the elderly care mode like smart community elderly care, smart home-based elderly care and smart institution elderly care, the group with blood type AB takes the highest proportion, followed by the group with blood type $\mathrm{O}$, but for the former, the group with blood type A takes the lowest proportion. For the latter two old-age care patterns, the proportion of the people with blood type $\mathrm{B}$ is the lowest.

In addition, it has also been analyzed above that occupational identity has a significant negative impact on the smart old-age care mode, and the degree of impact of occupational identity on the smart elderly care mode is shown in Figure 16-18. Obviously, among the smart community elderly care, smart home-based old-age care and smart institution old-age care, people prefer the smart community old-age care, followed by the smart homebased old-age care, and finally the smart institution oldage care. In addition, civil servants account for the highest proportion of each type of smart old-age care, followed by public institutions or people with certain occupations, such as employees of enterprises and workers in the tertiary industry.

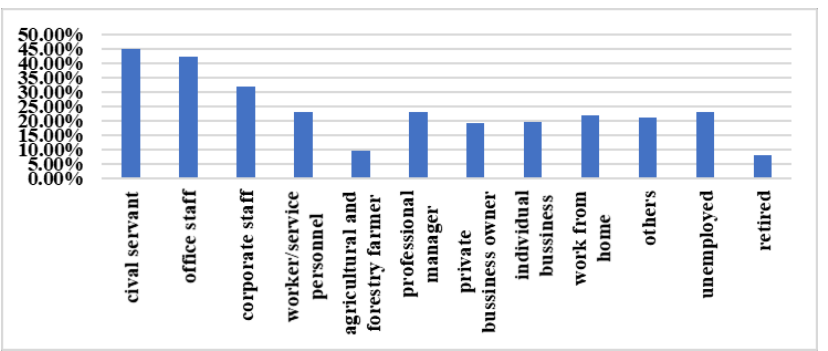

Figure 16. Proportion of the occupations choosing smart community for the aged. 


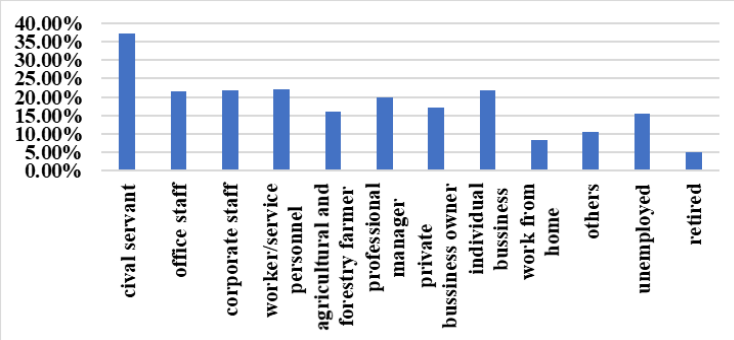

Figure 17. Proportion of occupations choosing smart home for the aged.

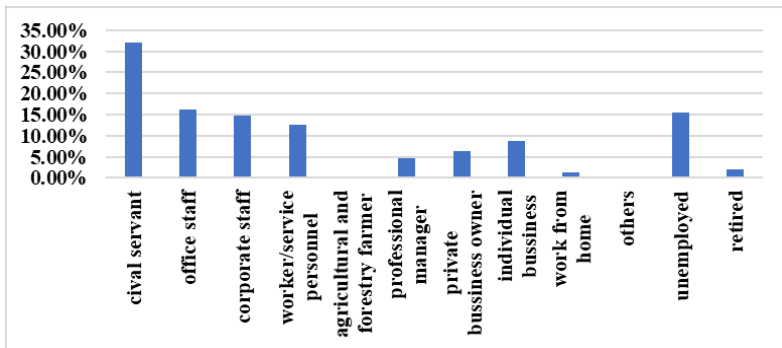

Figure 18. Proportion of the occupations choosing smart care institutions for the elderly.

For the people aged 60 or above, education level and age will have a significant impact on the ways of smart elderly care.

In the previous linear regression, it can be seen that educational level has a positive impact on the way of intelligent care for the aged. The specific results are shown in Figure 19-21. Obviously, the higher the educational level is, the higher the recognition degree of people for smart community, smart home and smart care institution for the aged is. However, according to the order of recognition degree, the smart community elderly care way is the first, the smart home-based elderly care way is the second, and the last is the smart institution elderly care way.

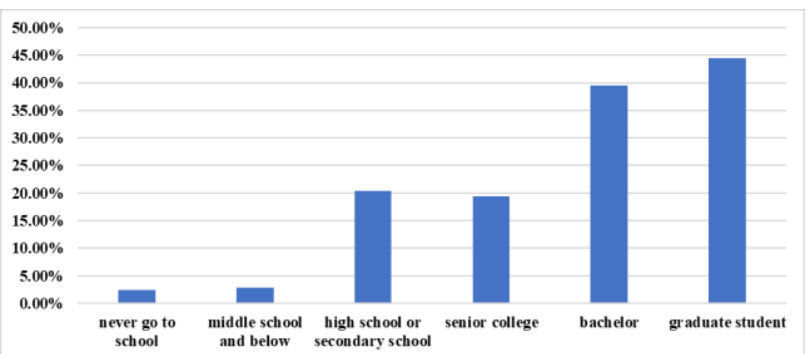

Figure 19. Proportion of people at all educational levels choosing smart community for elderly care.

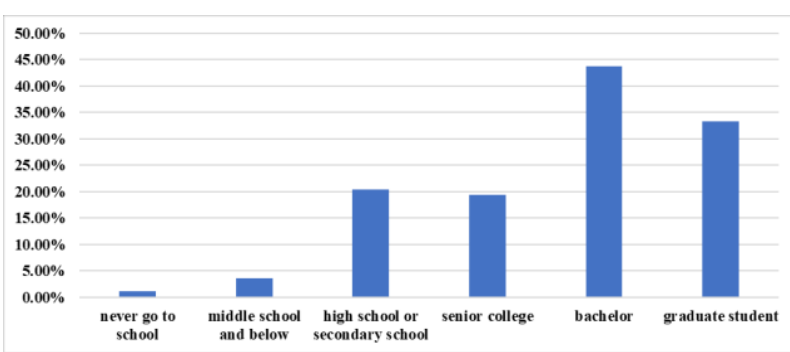

Figure 20. Proportion of people of all educational levels choosing smart home for the aged.

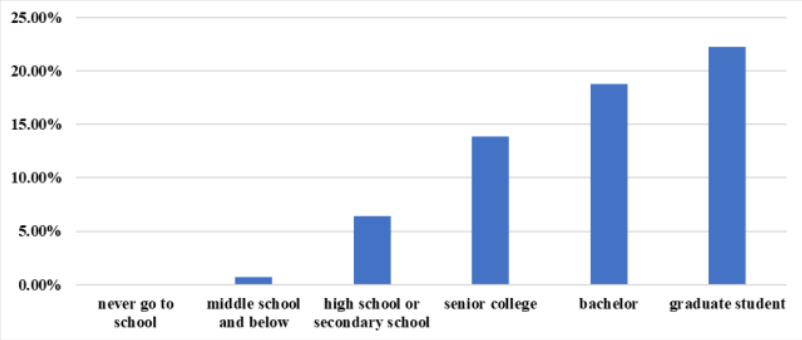

Figure 21. Proportion of people at all educational levels choosing smart elderly care service institutions.

According to the results of the previous regression analysis, the age of the people has a significant negative impact on the way of smart old-age care. The specific degree of influence is shown in Figure 22-24. It can be seen that as people get older, they are less likely to choose an intelligent old-age care mode.

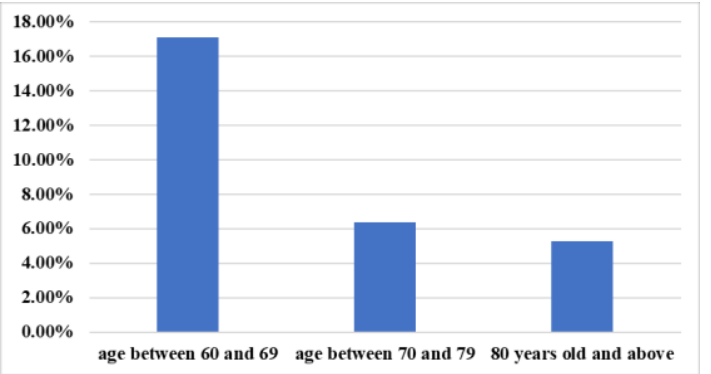

Figure 22. Proportion of people of all ages choosing smart community for elderly care.

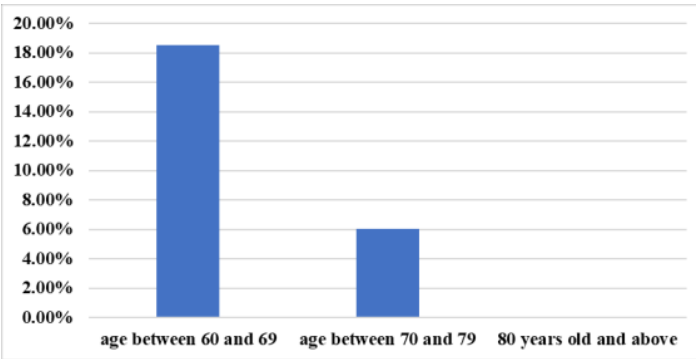

Figure 23. Proportion of people of all ages choosing smart home for the aged.

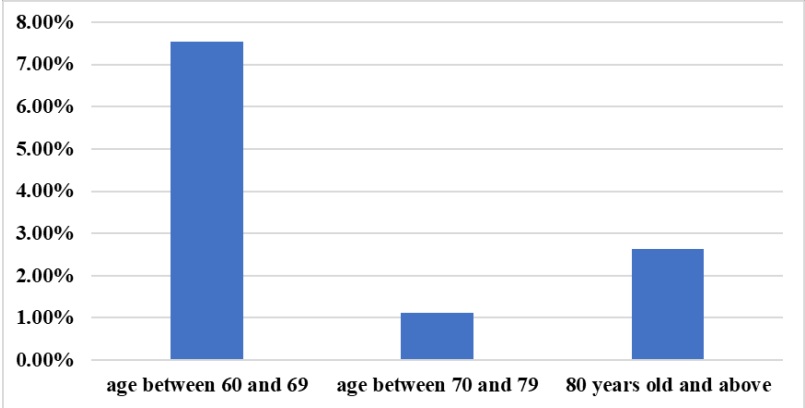

Figure 24. Proportion of people of all ages choosing smart pension institutions for the elderly.

However, according to the survey results of the people aged 60 and above, it is obvious that, relatively speaking, the elderly prefer the smart home-based care, then the smart community elderly care, and finally the smart institution elderly care. 


\section{SUGGESTIONS ON THE DEVELOPMENT OF THE AGED CARE INDUSTRY}

According to the analysis of multiple linear regression model, we can know that age, educational level, blood type and occupational identity will have a significant impact on the intelligent aged care. As age has a negative impact on the smart aged care, the more young people are, more likely to accept the smart aged care model.

Compared with the way of smart aged care institutions, people prefer the way of smart community aged care or smart home-based aged care. And these are directly or indirectly affecting the development of the present or potential elderly care industry.

Therefore, according to the age structure, educational background structure, blood type distribution and occupational identity distribution of local residents, the regions need to formulate long-term, medium and shortterm plans for the smart elderly care mode and related industries in this region under the condition of determining the overall goals. The specific suggestions are as follows:

\subsection{Building an integrated smart community aged care model and promoting the development of the upstream and downstream elderly care industry.}

In integrated intelligent community, in addition to build community hardware and software infrastructure such as fast and powerful in search engine Internet of Thing in community, intelligent community care applications system, greening, online-offline community hospitals, online-offline supermarkets, community health, goods bargain and recreation centers and canteen, smart community not only has the auxiliary intelligent robot which considers the elderly convenient movement and the routine body examination, but also need to install intelligent home which can be controlled by human, provide intelligent order service, and enlarged health services such as remote disease diagnosis and intelligent nursing. Meanwhile, it also provide the matching day-care program or basic health counseling, etc.

\subsection{Building integrated smart home-based aged care model or integrated smart home- based aged care service center.}

Because the economic situation of each family is different, each family can build its own smart home according to its financial capacity. For example, the family installs an intelligent monitoring system or intelligent care system at home so that another member of the family can remotely check the daily living situation of the elderly at home. At the same time, the smart home can solve the problems that the elderly can't solve at home through the convenience services provided by the community, the emergency rescue provided by the community hospital for the elderly, the senior nursing workers, psychological counselors, etc. Furthermore, the family may install the intelligent large screen similar to the auxiliary robot in function to facilitate the remote physical condition monitoring or disease diagnosis of the elderly, or provide the required services for the elderly at home through the special intelligent home care service center.

\subsection{Integrating, adjusting and improving the existing old-age care institutions, improving the old-age care model of intelligent aged care institutions to provide diversified healthy life and continued education for the elderly.}

The existing aged care institutions should improve or install intelligent facilities that are conducive to the physical and mental health and life convenience of the elderly, build eco-green health environment and life, increase or improve the services of the intelligent robots that monitor the daily physical situation of the elderly and assist them in walking. This kind of intelligent robot can provide the service that one robot deals with multiple elderly people, which not only improves the utilization of the smart robot, but also reduces the operating cost of the old-age care agency. Of course, the smart aged care institution should also provide the professional skills training for the nurses to finish the professional works that the robot can't complete. After all, the quality of the care is very important for the elderly and the families with the elderly. For example, Chou S, Boldy D, Lee A H, et al(2003) suggest that staff satisfaction plays a vital role in determining resident satisfaction in nursing homes[13]. In addition, the smart agency should provide fitness and entertainment centers for the elderly. If possible, it can also enhance or cultivate interests and hobbies of the elderly in the form of training or going to college for the aged to attract the elderly to their intelligent institutionscare, so as to improve people's demand for intelligent aged care institutions and improve the happiness of the elderly at a lower cost.

Overall, the demand for intelligent products in the elderly care industry provides physical and mental health for The healthy life and movement convenience of the elderly, while it also drives the development of the intelligent products with the Internet of Things, the demand for mental health consulting and intelligent care or advanced nursing. Therefore, the smart elderly care promotes the development of manufacturing industry with artificial intelligence technology like the Internet of things as the core, and also promotes the development of the primary industry such as ecological green and healthy agricultural food, and the development of the tertiary industry with the enlarged health as the center.

\section{CONCLUSION}

Intelligent aged care brings many changes to people's lives. It is very important to understand the factors that affect the way of intelligent elderly care. Through the multivariate linear regression analysis, it is known that for the aged 59 and below, their age, degree, blood type and occupational identity have a significant impact on the smart community and the smart home-based elderly care. 
The educational level, blood type and occupational identity have a significant effect on the way of smart oldage care institutions. For those aged 60 and older, educational level and age have a significant impact on the elderly care mode like smart communities, smart homes and intelligent aged care institutions. Therefore, each region needs to determine the leading aged care mode and the development direction of related industries in line with local characteristics according to the specific situation of the local residents, so as to benefit the people and improve people's life happiness.

\section{ACKNOWLEDGMENTS}

This work is supported by Opening Foundation of Jiangsu Population Association in 2019 (Grand No. JSPA2019011). It is sponsored by Qing Lan Project in Jiangsu Province in 2017 and Commerce Institute on the Belt and Road Initiatives in Wuxi.

\section{REFERENCES}

1. Li, X., Lu, R., Liang, X., Shen, X., Chen, J., \& Lin, X. 2011. Smart community: an internet of things application. IEEE Communications Magazine, 49(11), 68-75. DOI= http://dx.doi.org/10.1109/MCOM.2011.6069711

2. Saunders J, Syrdal D S, Koay K L, et al. 2016. "Teach Me-Show Me"-End-User Personalization of a Smart Home and Companion Robot. IEEE Transactions on Human-Machine Systems, 46(1), 27-40. DOI= http://dx.doi.org/10.1109/THMS.2015.2445105.

3. Stojkoska B R, Trivodaliev K. 2017. A review of Internet of Things for smart home: Challenges and solutions. Journal of Cleaner Production, Vol 140, 1454-1464. DOI= https://doi.org/10.1016/j.jclepro.2016.10.006.

4. Suryadevara N K, Mukhopadhyay S C. 2012. Wireless sensor network based home monitoring system for wellness determination of elderly. IEEE Sensors Journal, 12(6): 1965-

1972. DOI=http://dx.doi.org/ 10.1109/JSEN.2011.2182341
5. Wong A M, Chang W, Ke P, et al. 2012. Technology Acceptance for an Intelligent Comprehensive Interactive Care (ICIC) System for Care of the Elderly: A Survey-Questionnaire Study. PLOS ONE, 7(8).

DOI=http://dx.doi.org/10.1371/journal.pone.004059 1

6. Salman, L., Salman, S., Jahangirian, S., Abraham, M., German, F., Blair, C., \& Krenz, P. (2016). Energy efficient IoT-based smart home. the internet of things, 526-529, DOI=http://dx.doi.org/ 10.1109/WF-IoT.2016.7845449.

7. Dawadi, P. N., Cook, D. J., \& Schmitteredgecombe, M. 2016. Automated Cognitive Health Assessment From Smart Home-Based Behavior Data. IEEE Journal of Biomedical and Health Informatics, 20(4), 1188-1194. DOI=http://dx.doi.org/ 10.1109/JBHI.2015.2445754

8. Ransing, R. S., Rajput, M. 2015. Smart home for elderly care, based on Wireless Sensor Network. international conference on nascent technologies in engineering, 1-5.

DOI=http://dx.doi.org/10.1109/ICNTE.2015.702993 2

9. Furukawa, T. 1927. A study of temperament by means of human blood groups. Japanese Journal of Psychology, 2, 612-634.

10. Jogawar, V. V.1983. Personality correlates of human blood groups. Personality and Individual Differences, $4(2): 215-216$. DOI= https://doi.org/10.1016/01918869(83)90026-0

11. Jackson J J, The effects of educational experiences on personality trait development. https://www.ideals.illinois.edu/bitstream/handle/214 2/26149/Jackson_Joshua.pdf

12. Zhang Y., Xu L.. 2016. Demand-Side Study: Elders' Demand for Intelligent Care and Factors Influencing Their Demand. Scientific Research on Aging, , 4(07):43-52.

13. Chou, S., Boldy, D., \& Lee, A. H. 2003. Factors Influencing Residents' Satisfaction in Residential Aged Care. Gerontologist, 43(4), 459-472. DOI=http://dx.doi.org/10.1093/geront/43.4.459 